\title{
Morphofunctional analysis of the stomatognathic system in conventional complete dentures users from the Integrated Health Center
}

1) Universidade Potiguar, Natal, Rio Grande do Norte, Brazil.

Conflict of interest: Nonexistent

Received on: April 18, 2017

Accepted on: August 11, 2017

Mailing adress: :

Rodrigo Alves de Andrade

Rua Frei Alberto Cabral, 423, Centro -

Nova Cruz, Rio Grande do Norte, Brasil

CEP: $59215-000$

E-mail: rodrigoaandrade10@gmail.com fonoaudiologoandrade@gmail.com
Rodrigo Alves de Andrade(1)

Maria Deluana da Cunha ${ }^{(1)}$

Ana Maria da Costa dos Santos Reis ${ }^{(1)}$

\section{ABSTRACT}

This study aimed at characterizing the speech and chewing of users of conventional complete dentures (CCD) before and after speech therapy and prosthetic functional adaptation. The participants consisted of 10 users, divided into two groups: experimental (G1) and control (G2). Both groups underwent the same speech therapy and chewing evaluation before and 15 days after prosthetic functional adaptation; G1 underwent speech therapy in the period before prosthetic functional adaptation, and G2 underwent prosthetic functional adaptation without speech-language intervention. As observed, G1 presented 60\% of participants with phonetic and/or articular distortions and inadequate cut of the food and $80 \%$ with unilateral chewing; after therapy, no speech and masticatory alterations were observed, but the altered cut was seen in $100 \%$ of the group. In G2, $80 \%$ of the participants had speech and chewing alterations and $40 \%$ had an inadequate cut. After the therapy period, $60 \%$ of the subjects remained with speech alterations and $100 \%$ with altered cut and chewing alterations. It can be concluded that after prosthetic functional adaptation, the group that underwent speech therapy did not present the alterations initially detected, except for the cut of the food, as opposed to G2 in which the changes persisted, showing that prosthetic rehabilitation alone, did not reestablish functional patterns, speech-language intervention being required.

Keywords: Stomatognathic System; Speech Therapy; Dental Prosthesis 


\section{INTRODUCTION}

The Stomatognathic System (SS) is composed of static structures (mandible, maxilla, dental arches, TMJs and hyoid bone) and dynamic structures (masticatory, supra and infrahyoid muscles and tongue, lips and cheek muscles) that act together ${ }^{1}$ as they are balanced and controlled by the central nervous system performing the stomatognathic functions: suction, breathing, swallowing, speech and chewing.

Speech is one of the main means of social interaction, and its production is closely related to the morphology of the stomatognathic system, in which the teeth, bones and muscular groups play a fundamental role for determination of acoustic and articulatory patterns ${ }^{2}$. An effective mastication requires balance between SS structures.

Chewing is one of the most important functions of the Stomatognathic System, since it starts the process of feeding, grinding and preparing the food, favoring swallowing and digestion, and consequent quality of nutrition. Efficient chewing requires the balance of SS structures, including muscles, teeth and bones $^{3}$. Chewing should occur after cutting the food with the incisors, with closed lips, without noise or exaggerated participation of the perioral musculature, with lateralization and alternating bilateral mastication, with rotational movements of the mandible and with muscular strength symmetry ${ }^{4}$.

It is noteworthy that despite advances in dentistry, Brazilian people still present a high incidence of tooth loss, be it partial or total. The number of Complete Dentures (CDs) will grow around $2.0 \%$ by 2020 , what represents an increase of approximately 300 thousand individuals requiring $\mathrm{CDs}^{5}$.

Edentulism induce changes in the SS, especially in the maxillomandibular relationship and in the shape of bone structures that cause a neuromuscular imbalance, hindering the correct performance of stomatognathic functions, and also likely to interfere in the adaptation of the dental prosthesis ${ }^{3}$. Moreover, the vertical dimension of occlusion (VDO) also changes, affecting the aesthetic appearance and postural condition of edentulous patients.

Besides the aesthetic benefit, dental prostheses present prospects of improvement for the stomatognathic functions of speech, chewing and swallowing. However, prosthetic adaptation may be impaired by oromiofunctional alterations, as well as the stomatognathic functions may be altered to the detriment of the condition and type of dental prosthesis ${ }^{3}$, what suggests the need and importance of an integrated work with Speech Therapy.

Speech therapy, as part of the interdisciplinary team, can contribute to the prosthetic adaptation and rehabilitation of stomatognathic functions within the limitations found, so as to provide a better quality of life of the affected subjects ${ }^{6}$.

The aim of this study was to characterize the speech and chewing of users of conventional complete dentures before and after speech therapy and prosthetic functional adaptation in a collaborative work between Speech Therapy and Dentistry.

\section{Case Report}

Descriptive research of longitudinal and interdisciplinary character, of the case report type, developed with total edentulous individuals using Conventional Complete Dentures (CCD) and assisted at the Integrated Health Center $(\mathrm{IHC})$ of the Institution of origin, between June and November 2015. The sutdy was approved by the Ethics and Research Committee of the Potiguar University - UnP under Opinion no $1,065,231 / 2015$.

From a universe of 126 subjects who received assistance between the months established in the research, only 10 composed the sample, after checking inclusion and exclusion criteria. The inclusion criteria were: patients with age range between 40 and 75 years, who sought the Dentistry service of the institution for adaptation of Conventional Complete Dentures. The exclusion were: subjects who presented dentofacial deformities, neurological and cognitive problems, users of medications that could trigger increase and/or decrease in salivation, who had previously undergone Speech Therapy, and with moderate to severe hearing loss ( $>56 \mathrm{~dB}$ ) according to audiometry, because hearing loss at this intensity may cause distortions that may be confused with probable changes resulting from a maladaptive prosthesis.

For audiometry, an interacoustic audiometer model AC40, calibrated in January 2015, was used in an acoustic booth manufactured by Televox, model Média, serial number 2286, with test on January 9, 2015. The sample consisted of a literate population of 7 selfdeclared white women, 1 brown woman, and 2 white men, aged 43 to 73 years, of which 7 already used upper and lower CCD, 2 used only superior denture, and 1 was going to start using the denture. All participants received information on the research stages and signed the Informed Consent Term. 
The initial evaluation occurred between May 27 and 29 and July 8, 9, 15 and 16, when the protocol of Orofacial Assessment for Users of Dental Prostheses adapted by KALIL, MTAC; CAVALCANTI, RVA \& BIANCHINI, EMG was applied (1) (APPENDIX 1), 11 phrases balanced with words of different syllabic extensions and predominance of the fricative phonemes $|s|,|z|, \mid c h l$ and ljl (2), 19 phrases characterized by the predominance of the same phoneme of the Brazilian Portuguese language proposed by Berretin Apud Cunha (2004) (3), in which the volunteers were instructed to read the phrases aloud and judge the difficulty to pronounce them attributing a score from 0 to 10 , with 10 for the most difficult phrase to pronounce.

Concerning speech alterations, the presence or absence of omissions or substitutions of phonemes, alteration of articulatory points, lispings, changes in speech integ- rity and amplitude of mandibular movements were investigated.

The applicability of the protocol was made through the anatomo-functional observation of the static structures (maxilla, mandible, TMJ and dental arches) and dynamic structures (masseter, buccinator, and mentual muscles, lips and tongue) of the stomatognathic system, palpation, counter-resistance using wooden spatula, verbal commands of mobility (opening, closure, protrusion, retraction, lateralization and vibration) and facial measurement using a $150 \mathrm{~mm}$ plastic caliper/ 6 in. DISMA.

The masticatory function was personally assessed by two evaluators and analyzed through photographic records and filming by a third evaluator. French bread (salt bread) baked in the previous day was used for this analysis, requesting that the subject chewed five times in a habitual way. Only the last four chews were considering, however, because the participant could direct the mastication in an attentive and controlled manner, as he or she was under evaluation and filming, according to the proposed protocol ${ }^{7}$.

During chewing, the type of food cut (anterior, lateral, hand or tear), chewing type (unilateral or bilateral, simultaneous or alternating) and lip position during mastication were analyzed, as well as the number of masticatory cycles of each of the four portions, considering the average of this variable.

Equal masticatory cycles for both sides; cut of the food in the anterior region, with the central and lateral incisors; bilateral mastication with alternating movements and lip sealing during the whole mastication, were considered appropriate for greater reliability of the evaluation. To characterize the proposed masticatory type ${ }^{8}$, the number of cycles performed on each side (right and left) in the 4 portions analyzed was counted, considering unilateral mastication when more than $66 \%$ of the cycles occurred predominantly on the same side of the 4 portions, and bilateral when presented with less than $66 \%$ of the masticatory cycles in the total of 4 portions.

The sentences were read, recorded and analyzed by the three evaluators. All procedures were performed using gloves, obeying the principles of biosafety, and photographed and filmed by a digital $S O N Y{ }^{\circledR} N 50$ MODEL No. SEL $16 F 28$.

The study sample was divided into two groups, G1 (Experimental Group) and G2 (Control Group), with 05 users each, selected for convenience. G1 patients underwent initial evaluation, speech-language therapy pre-installation of the prosthesis and final evaluation 15 days after prosthetic functional adaptation; and G2 patients underwent initial evaluation, prosthetic installation and final evaluation 15 days after prosthetic functional adaptation. Cases of presence of alteration after functional adaptation would receive a speechlanguage intervention. Both groups (G1 and G2) underwent dental follow-up in order to reestablish the Vertical Dimension of Occlusion - VDO and recover the lip and aesthetic support, and speech therapy with the purpose of rehabilitating the oromiofunctional alterations found, promoting prosthetic adaptation.

Concomitantly to dental care, G1 participants underwent speech therapy for a month and a half, totaling 6 sessions (at weekly basis, for one hour each) and G2 participants for one month, totaling 4 sessions (at weekly basis, for one hour each). Therapy was based on isometric, isotonic and isokinetic exercises, in addition to the training of stomatognathic speech and chewing functions ${ }^{9,10}$, by alternating bilateral masticatory training, perception, production and automatization of target phonemes, stretching of the muscle fiber of the tongue, inductive massages in the opposite direction, contraction of the muscular fiber of the facial mime, using touches with pressure and discontinuous vibration performed for both groups and selected according to the changes of each individual.

Because of the $n=10$, the results were described in a descriptive way through tables and graphs, and statistical analysis was not necessary. 


\section{RESULTS}

The research universe was based on 126 subjects of the IHC waiting list, of whom 116 were excluded (80 because they were partial denture users, 12 because they had already made the prostheses or had no interest in the making them, and 24 because they did not answer the calls). The sample was made up of 10 individuals, who were equally distributed into two groups, G1 and G2.

It was found that the majority $(60 \%)$ had lost all their teeth more than twenty years ago. As for the time using a same single denture, it was observed that nine $(90 \%)$ individuals used to keep the same denture for more than four years. Seven participants $(70 \%)$ used upper and lower complete dentures, two (20\%) used only upper denture, and only one (10\%) was going to use the denture for the first time. It was found that more than half $(60 \%)$ tended to have a mesocephalic face, while $20 \%$ had dolichocephalic and $20 \%$, brachycephalic face.

Table 1 shows the characterization of orofacial structures (lips, tongue, cheek, masseter) with respect to mobility and tonicity of $\mathrm{G} 1$ and $\mathrm{G} 2$ subjects since the initial evaluation (with the old prosthesis). There was a predominance of change in lingual mobility ( $80 \%$ in G1 and $20 \%$ in G2); lip tone (hypotonia) $(60 \%$ in $\mathrm{G} 1$ and G2); cheek tone (one- or two-sided hypotonia) (80\% in G1 and $60 \%$ in G2) and masseter hypotonia (100\% in G1 and G2).

Table 1. Characterization of orofacial structures regarding mobility and tonicity in the initial evaluations and 15 days after using the prosthesis

\begin{tabular}{|c|c|c|c|c|c|c|c|c|c|c|}
\hline & \multirow{3}{*}{ Structures } & & \multicolumn{4}{|c|}{ Initial/final evaluation } & \multicolumn{4}{|c|}{ Initial/final evaluation } \\
\hline & & & \multicolumn{2}{|c|}{ G1 } & \multicolumn{2}{|c|}{ G1 } & \multicolumn{2}{|c|}{ G2 } & \multicolumn{2}{|c|}{ G2 } \\
\hline & & & Qty & $\%$ & Qty & $\%$ & Qty & $\%$ & Qty & $\%$ \\
\hline \multirow{4}{*}{ Tongue } & Tonicity & Altered & 2 & $40 \%$ & 0 & $0 \%$ & 0 & $0 \%$ & 0 & $0 \%$ \\
\hline & & Normal & 3 & $60 \%$ & 5 & $100 \%$ & 5 & $100 \%$ & 5 & $100 \%$ \\
\hline & Mobility & Altered & 4 & $80 \%$ & 0 & $0 \%$ & 1 & $20 \%$ & 0 & $0 \%$ \\
\hline & & Normal & 1 & $20 \%$ & 5 & $100 \%$ & 4 & $80 \%$ & 5 & $100 \%$ \\
\hline \multirow{4}{*}{ Lips } & Tonicity & Altered & 3 & $60 \%$ & 0 & $0 \%$ & 3 & $60 \%$ & 0 & $0 \%$ \\
\hline & & Normal & 2 & $40 \%$ & 5 & $100 \%$ & 2 & $40 \%$ & 5 & $100 \%$ \\
\hline & Mobility & Altered & 1 & $20 \%$ & 0 & $0 \%$ & 1 & $20 \%$ & 1 & $20 \%$ \\
\hline & & Normal & 4 & $80 \%$ & 5 & $100 \%$ & 4 & $80 \%$ & 4 & $80 \%$ \\
\hline \multirow{4}{*}{ Cheek } & Tonicity & Altered & 4 & $80 \%$ & 0 & $0 \%$ & 3 & $60 \%$ & 2 & $40 \%$ \\
\hline & & Normal & 1 & $20 \%$ & 5 & $100 \%$ & 2 & $40 \%$ & 3 & $60 \%$ \\
\hline & Mobility & Altered & 4 & $80 \%$ & 0 & $0 \%$ & 1 & $20 \%$ & 2 & $40 \%$ \\
\hline & & Normal & 1 & $20 \%$ & 5 & $100 \%$ & 4 & $80 \%$ & 3 & $60 \%$ \\
\hline \multirow{2}{*}{ Masseter } & Tonicity & Altered & 5 & $100 \%$ & 0 & $0 \%$ & 5 & $100 \%$ & 4 & $80 \%$ \\
\hline & & Normal & 0 & $0 \%$ & 5 & $100 \%$ & 0 & $0 \%$ & 1 & $20 \%$ \\
\hline
\end{tabular}

G1- Group 1, G2- Group 2, Qty - Quantity and \% - Percentage

The results of the initial evaluation on the chewing test showed a predominance of unilateral alternating chewing pattern observed in eight subjects $(80 \%)$, while the bilateral alternating chewing pattern was seen in only one subject (10\%); one participant (10\%) was unable to complete the chewing test, reporting impossibility of chewing with the prosthesis he was using.

Only four (40\%) individuals were observed to perform the anterior cut of the food (with the central and lateral incisors), one (10\%) tore it with the lateral incisors, four $(40 \%)$ tore the food with the hand, and one $(10 \%)$ was unable to complete the chewing test. Of these, $40 \%$ had the food cut properly, $50 \%$ improperly, and $10 \%$ did not complete the test.

Before the initial evaluation some participants demonstrated speech alterations, either changes of articulatory points, lisps, speech unintelligibility and/or diminution of the amplitude of mandibular movements; seven subjects $(70 \%)$ presented one or more of these phonetic changes and only three $(30 \%)$ showed no alterations in these aspects. 
The main alterations found were interdentalizations /t/ /d/ in (20\%) of individuals, distortion of /r/ (10\%), decrease in articulatory amplitude (30\%), anterior lisp (20\%), lateral lisp (10\%), distortion of /f/, /v/, /s/ and /"j"/ (20\%), distortion of /"ch"/ (40\%) and no change (30\%).

Figure 1 presents the judgment about the difficulties of pronunciation listed by the subjects before the 23

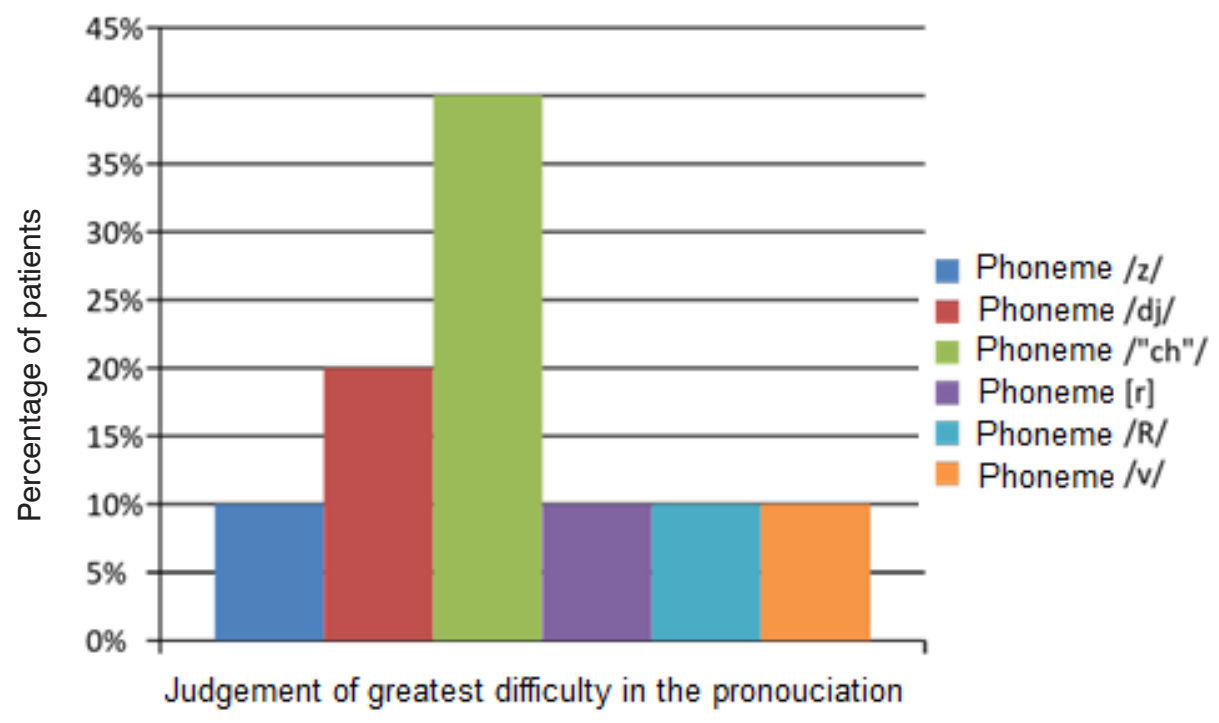

phonemes of the Brazilian Portuguese language ${ }^{11}$. In the evaluation, the phoneme chosen as having the most difficul pronouciation was the /"ch"/ (4 subjects $40 \%$ ), also confirmed in speech - language evaluation, followed by the affiliated phoneme /"dj"/ (2 subjects $20 \%$ ), in the same proportion for the phonemes /z/, /v/, /R/ and [r] (each with 10\%).

Figure 1. Judgment of pronunciation - phoneme considered the most difficult one in the initial evaluation

The comparison of the initial and final chewing evaluation presented in Table 2 showed that the G1, which underwent speech therapy prior to the installation of the new prosthesis, achieved adequate mastication (alternating bilateral chewing with labial sealing), cutting the food with the hand, which corroborates another study ${ }^{3}$. Regarding the G2, which had not undergone previous therapy, there was a predominance of alternating unilateral chewing, with lip sealing and food cutting with the hand.
Table 3 presents the comparison between the aspects of the initial and final speech evaluation (after prosthetic functional adaptation) per subject. The results showed phonetic and/or articular distortions in three individuals $(60 \%)$ in the G1 and four $(80 \%)$ in the G2 with in the initial evaluation, and no individual $(0 \%)$ in the $\mathrm{G} 1$ and three $(60 \%)$ in the $\mathrm{G} 2$ in the final evaluation. 
Table 2. Characterization of mastication in the initial and final evaluations

\begin{tabular}{|c|c|c|c|c|c|c|c|}
\hline \multicolumn{8}{|c|}{ Final chewing evaluation } \\
\hline \multirow{2}{*}{\multicolumn{2}{|c|}{ Subjects }} & \multicolumn{3}{|c|}{ Cut } & \multicolumn{2}{|c|}{ Type } & \multirow{2}{*}{$\mathrm{L} / \mathrm{P}$} \\
\hline & & A & W/H & $\mathbf{T}$ & BI & UNI & \\
\hline \multirow{5}{*}{ GROUP 1} & SUB 1 & & $X$ & & \multirow{5}{*}{$x$} & $X$ & W/S \\
\hline & SUB 2 & & $x$ & & & $x$ & W/S \\
\hline & SUB 3 & $x$ & & & & & W/S \\
\hline & SUB 4 & & $x$ & & & $X$ & W/S \\
\hline & SUB 5 & $x$ & & & & $x$ & W/S \\
\hline \multirow{5}{*}{ GROUP 2} & SUB 6 & $X$ & & & & $x$ & W/S \\
\hline & SUB 7 & \multicolumn{6}{|c|}{ Did not complete the chewing test } \\
\hline & SUB 8 & $x$ & & & & $X$ & W/S \\
\hline & SUB 9 & \multirow{2}{*}{\multicolumn{2}{|c|}{$x$}} & & & $X$ & W/S \\
\hline & SUB 10 & & & $X$ & & $X$ & W/S \\
\hline \multicolumn{8}{|c|}{ Initial chewing evaluation } \\
\hline \multirow{2}{*}{\multicolumn{2}{|c|}{ Subjects }} & \multicolumn{3}{|c|}{ Cut } & \multicolumn{2}{|c|}{ Type } & \multirow{2}{*}{$\mathrm{L} / \mathrm{P}$} \\
\hline & & A & W/H & $\mathbf{T}$ & BI & UNI & \\
\hline \multirow{5}{*}{ GROUP 1} & SUB 1 & & $\mathrm{X}$ & & $X$ & & W/S \\
\hline & SUB 2 & & $x$ & & $x$ & & W/S \\
\hline & SUB 3 & & $X$ & & $x$ & & W/S \\
\hline & SUB 4 & & $X$ & & $x$ & & W/S \\
\hline & SUB 5 & & $x$ & & $x$ & & W/S \\
\hline \multirow{5}{*}{ GROUP 2} & SUB 6 & & $X$ & & & $X$ & W/S \\
\hline & SUB 7 & & $X$ & & & $x$ & W/S \\
\hline & SUB 8 & & $x$ & & & $x$ & W/S \\
\hline & SUB 9 & & $X$ & & & $x$ & W/S \\
\hline & SUB 10 & & & $X$ & & $X$ & W/S \\
\hline
\end{tabular}

A - Anterior, W/H- With the hand, T- Tear, BI- Bilateral, UNI- Unilateral, W/S - with lip sealing, L/P - Lip Posture and SUB- Subject

Table 3. Comparison per subject between initial and final speech

\begin{tabular}{|c|c|c|c|}
\hline \multirow{2}{*}{\multicolumn{2}{|c|}{ Subjects }} & Initial speech evaluation & Final speech evaluation \\
\hline & & Observed changes & Observed changes \\
\hline \multirow{5}{*}{ GROUP 1} & SUBJECT 1 & $\begin{array}{l}\text { 1. Interdentalization of /t/ and /d/; } \\
\text { 2. Distortion of }[r] \text {; } \\
\text { 3. Decreased articulatory amplitude. }\end{array}$ & 1. No Changes \\
\hline & SUBJECT 2 & 1. No changes & 1. No Changes \\
\hline & SUBJECT 3 & $\begin{array}{l}\text { 1. Anterior lisp /s/, /z/; } \\
\text { 2. Distortion of /ch/; } \\
\text { 3. Interdentalization of /t/ and /d/; } \\
\text { 4. Decreased articulatory amplitude. }\end{array}$ & 1. No Changes \\
\hline & SUBJECT 4 & 1. No changes & 1. No Changes \\
\hline & SUBJECT 5 & 1. Anterior and lateral lisp /s/ and /z/. & 1. No Changes \\
\hline \multirow{7}{*}{ GROUP 2} & SUBJECT 6 & 1. Distortion in the phonemes /s/, /j/, /ch/, /f/ and /v/. & $\begin{array}{l}\text { 1. Interdentalization of /t/ } \\
\text { 2. Lateral lisp /s/ } \\
\text { 3. Reduced articulation. }\end{array}$ \\
\hline & SUBJECT 7 & 1. No changes & 1. No changes \\
\hline & SUBJECT 8 & 1. Decreased articulatory amplitude. & 1. Interdentalization of $/ \mathrm{t} / \mathrm{d} / \mathrm{d} / \mathrm{and} / \mathrm{n} /$ \\
\hline & SUBJECT 9 & $\begin{array}{l}\text { 1. Distortion in the linguodental, bilabial, labiodental and palatal } \\
\text { phonemes due to absence of prosthesis. }\end{array}$ & 1. No changes \\
\hline & \multirow{3}{*}{ SUBJECT 10} & \multirow{3}{*}{ 1. Distortion of the phoneme /ch/ } & 1. Interdentalization of /d/ \\
\hline & & & 2. Lateral lisp /s/ \\
\hline & & & 3. Reduced articulation. \\
\hline
\end{tabular}




\section{DISCUSSION}

The literature reports that in Brazil, the 1986 national oral health survey revealed a mean number of teeth lost of $14.9(66.5 \%)$ in adults aged $35-44$ years and 23.4 (86\% of the index) in individuals aged $50-59$ years $^{12}$.

Prolonged use of complete dentures cause them to gradually lose quality, mainly from the fourth year onwards; after the eighth year of use, a large part of the patients end up with masticatory problems ${ }^{13}$. Patients usually show satisfaction with the conventional complete upper denture, but the lower one usually presents problems of retention and stability, causing dissatisfaction to the users ${ }^{14}$.

Edentulism affects motor and sensorial aspects of the masticatory process, favoring muscular atrophy, especially of the masseter ${ }^{3}$. Maladaptive dentures may lead to unilateral chewing pattern as a mechanism of protection and adaptation to structures, to avoid sequela $e^{15}$, what is consistent with our findings.

The presence of altered food cut in a significant number of subjects is in line with the literature. A study with a sample of 53 elderly individuals found that $71.9 \%$ users of complete denture and/or partial removable denture had altered food cut ${ }^{3}$.

Individuals who do not use dentures, or maladaptive denture wearers, present speech impairments ${ }^{16}$. In general, when the denture is not well adapted, it causes problems such as speaking with less opened mouth so as not to lose stability and this ends up causing articulatory imprecision. Decreased mandibular movements are also evident, as well as altered movements of the jaw and lips in an attempt to compensate for and improve speech accuracy ${ }^{17}$.

The difficulty in producing the phoneme /ch/ listed by part of the participants disagrees with the literature, in which the phoneme $/ \mathrm{s} /$ is pointed as the most affected, because the vertical and horizontal trespasses represent a mandibular path for its pronunciation ${ }^{18}$.

The findings of the G2 are in agreement with the literature, in which unilateral chewing prevails after the installation of the denture, supposedly because a previously acquired habit persists ${ }^{2}$. On the other hand, the results of the G1 differed from another study2; the speech therapy in the present research was followed by adaptation of the chewing patterns that persisted after installation of the new prostheses. This finding shows the importance of phonoaudiological monitoring for the structuring of functional patterns.

The values demonstrate the efficacy of phonoaudiological therapy on speech disorders in $\mathrm{G} 1$ and suggests that the prosthesis alone does not readjust the altered speech patterns, as seen in G2.

After the initial evaluation of both groups, the G1 was submitted to therapy in the period of preparation of the prostheses, whose protocol consists of six weekly 60 minutes sessions. The therapy timer $^{19}$ suggests a treatment time of less than 6 months, with a frequency of twice a week, and duration of 30 minutes each session, which fits the time adopted in the study. Only three $(60 \%)$ subjects attended all sessions and the others (40\%) performed only five, and missed one session. The aim of the therapies was to strengthen lingual musculature, buccinator, lips, masseter and musculature of the facial mime, as well as to work on tongue mobility, buccinator, bilateral mastication and speech training, as well as stretch the tongue musculature in the case of one subject (20\%) who had a short lingual frenulum. Exercises for mobility, tone, proprioception and function monitoring are necessary when using a prosthesis, to aid motricity to reach standards compatible with oral rehabilitation ${ }^{6}$.

After the final evaluation, the $\mathrm{G} 2$ required speech therapy (as indicated by changes shown in Tables 2 and 3), and this was performed in a similar manner to the therapeutic process in $\mathrm{G} 1$, with four weekly 60 minutes sessions (more sessions are unnecessary). All G2 participants required therapy, although only four were willing to do it, and one gave up therapy before starting. The therapies were mainly focused on the functional training of speech and chewing, but also adapting the musculature in cases where it was altered.

The exercises (common to both groups) were isometric, isotonic and isokinetic ${ }^{9,10}$, including masticatory training, perception, production and automation of target phonemes, stretching of the muscle fiber of the tongue, inducing massages in the opposite direction to the muscular fiber contraction of the facial mime, using pressing touches and discontinuous vibration (Appendix 2). Although not the main objective, at the end of the last session, the subjects reported improvement in speech, strengthening of the musculature, more balanced mastication with wider mandibular movements, thus confirming the evaluation that detected normotensive face musculature, adequate tongue tonicity and mobility for CCD users, intelligible speech, balanced articulation and bilateral chewing.

One of the important limitations of this study was the small number of participants $(n=10)$ using dentures who underwent phonoaudiological evaluation and 
could be included in the study. However, the same limitation has been also present in other speech therapy studies ${ }^{3,20}$. These data point again to the importance of interdisciplinary work, as well as of speech therapy evaluation integrated to the adaptation of the dental prosthesis.

Another bias to be discussed regards the heterogeneity of the sample, in which 7 used upper and lower CCD, 2 used only upper denture, and 1 was going to use the prosthesis for the first time. Because they presented distinct patterns and adaptations, the comparison of some variables presented limitations. The inclusion of these subjects was due to the limited number of CCD users who sought the dentistry service of the institution studied. More homogeneous samples are recommended for the next studies.

\section{CONCLUSION}

The methodology employed in the present study allowed to detect in initial moments, in both groups, changes in tonicity and mobility of oromiofunctional structures, predominance of unilateral mastication, inadequate food cut and speech changes of the interdentalization type of $/ \mathrm{t} /$ and $/ \mathrm{d} /$, anterior lisp $/ \mathrm{s} /$ and $/ z /$, distortion of the phoneme $/ \mathrm{ch} /$ and decreased articulatory amplitude. After the prosthetic functional adaptation, the group that had undergone speech therapy (G1) did not present the alterations initially found, except for the cut of the food, suggesting the efficacy of the therapy used. On the other hand, the changes persisted in the G2, because functional adaptation alone did not reestablish functional patterns, requiring phonoaudiological intervention.

\section{ACKNOWLEDGMENTS}

We thank all the dentistry team of the institution that allowed us to develop this multiprofessional work.

\section{REFERENCES}

1. Brito DO. Análise da fala, do tônus muscular orofacial e das mobilidades dos lábios, da língua e da mandíbula em usuários de prótese total superior. [monografia na internet], Universidade de Taubaté; 2010 [acesso em 08 mar 2015]. Disponível em: http://www.bdtd.unitau.br/tedesimplificado/tde_ arquivos/6/TDE-2012-11-05T132816Z-350/Publico/ Daniele\%20de\%20Oliveira\%20Brito.pdf
2. Cunha CP. Dificuldade para pronunciar e a relação com a avaliação miofuncional em usuários de prótese total. [monografia na internet], Ribeirão Preto; 2004 [acesso em 12 mar 2015]. Disponível em: https://mail-attachment. googleusercontent.com/attachment/u/0/?ui= $2 \& i k=a d 843 f 0 b f 7 \& v i e w=a t t \& t h=14 c 056 c 59 a$ e8cb88\&attid $=0.3 \&$ disp $=$ inline \& realattid $=f$ i72fv0vz2\&safe $=1 \& z w \&$ saduie $=$ AG9B_P8wyeaH 9 NZ5U7Fyb6PI2RtK\&sadet $=1427500258925 \&$ sadat $=$ ANGjdJ_RN8WYCzw-Z6Q0r4ZBaDvpFOgaCM4kf 6MvLKCdnTBB6HScKWh_aViyVNc\&sads=jeKw1G z4BifMvzfaGhU9E2C3WSg

3. Cavalcanti RVA, Bianchini EMG. Verification and morfofunctional analysis of mastication characteristics in individuals using removable dental prosthesis. Rev. CEFAC [Internet]. 2008 Dez [acesso em 12 Mar 2015]; 10(4): 490-502. Disponível em: http://www.scielo.br/scielo.php?script $=$ sci abstract\&pid $=$ S1516-18462008000400009\&Ing $=e$ n\&nrm $=$ iso\&tlng $=$ en

4. Medeiros AMC, Medeiros M. Motricidade Orofacial: Inter - relação entre Fonoaudiologia \& Odontologia. São Paulo: LOVISE, 2006.

5. Telles DM. Prótese Total Convencional e sobre Implantes. São Paulo: Santos Editora, 2009.

6. Felício CM, Cunha CC. Relações entre Condições Miofuncionais Orais e Adaptação de Próteses Totais. Revista Ibero-americana de Prótese Clínica e Laboratorial; 2005 [acesso em10 mar 2015] 7(36): [p.195-202]. Disponível em: https:// mail-attachment.googleusercontent.com/ attachment/u/0/?ui $=2 \& i k=a d 843 f 0 b f 7 \& v i e w=a t t \&$ th $=14 \mathrm{c} 056 \mathrm{c} 59 \mathrm{ae} 8 \mathrm{cb} 88 \&$ attid $=0.1 \&$ disp $=$ inline $\& r$ ealattid $=f \_i 72 f v 0 v e 0 \&$ safe $=1 \& z w \&$ saduie $=A G 9 B$ P8wyeaH9NZ5U7Fyb6PI2RtK\&sadet $=1427494146$ 922\&sadat $=$ ANGjdJ-7NoWvo1gwc5NEQ1 tgujDzSc XUPp4jWDGUDIF5MLB382ygB2ZaHYNaRFY\&sad $\mathrm{s}=$ EgY09L_4FflAVcKXzaaNzXoBoes

7. Kalil MTAC, Cavalcanti RVA, Bianchini EMG. Protocolo de Avaliação Miofuncional Orofacial para Usuários de Próteses Dentárias. In: Anais Suplemento especial da Revista da Sociedade Brasileira de Fonoaudiologia. 16으 Congresso Brasileiro de Fonoaudiologia; 2008 Set 24-27; Campos do Jordão, São Paulo, 2008. Disponível em: http://www.sbfa.org.br/portal/anais2008

8. Whitaker ME. Função Mastigatória: proposta de protocolo de avaliação clínica [dissertação]. Bauru (SP): Universidade de São Paulo; 2005. 
9. Rahal A. Exercícios utilizados na Terapia de Motricidade Orofacial (quando e por que utilizá-los). In: Marchesan IQ, Silva HJ da, Berrentin-Félix G. Terapia Fonoaudiológica em Motricidade orofacial. São Paulo: Pulso Editorial; 2012. p. 43-50.

10. Berretin-Félix G, Silva NMA, Mituuti CT. Terapia Fonoaudiológica em Deglutição (como eu trato). In: Marchesan IQ, Silva HJ da, Berretin-Félix G. Terapia Fonoaudiológica em Motricidade Orofacial. São Paulo: Pulso Editorial; 2012. p. 147-62.

11. Yavas M, Hernandorena CLM, Lamprecht RR. Avaliação fonológica da criança. Porto Alegre: Artes Médicas; 1991. p. 36.

12. Peres MA, Barbato PR, Reis SCGB, Freitas CHSM, Antunes JLF. Perdas dentárias no Brasil: análise da Pesquisa Nacional de Saúde Bucal 2010. Rev Saúde Pública; 2013 [acesso em 04 nov 2015]; Disponível em:http://www.revistas.usp.br/rsp/ article/view/76756

13. Yoshizumi DT. An evaluation of factors pertinent to the success of complete denture service. Rev. The JPD [Internet]. 1964 [acesso em 06 Nov 2015]; 14: 866-78. Disponível em: http://www.thejpd.org/ article/0022-3913(64)90015-0/abstract

14. Jacometti PM. Análise das possibilidades reabilitadoras contemporâneas para pacientes edentados totais: uma revisão de literatura [monografia na internet]. Porto Alegre: Universidade Federal do Rio Grande do Sul, 2011 [acesso em 04 nov 2015]. Disponível em: http://www.lume.ufrgs. br/handle/10183/35598

15. Molina OF. - Fisiopatologia craniomandibular: oclusão e ATM [monografia na internet]. São Paulo: Pancast, 1989 [acesso em: 06 nov 2015]. Disponível em: http://www.cefac.br/library/teses/1c abb4ab22ec0c080d7da62069131570.pdf

16. Rosa RR, Berretin-Felix G. Fala e reabilitação oral protética: revisão integrativa. Distúrb Comum. São Paulo, 2015 [acesso em 04 nov 2015] 27(1): [p.8]. Disponível em: http://revistas.pucsp.br/index.php/ dic/article/view/19210/16337

17. Marchesan IQ. Tratado em fonoaudiologia da SBFa - alterações de fala de origem musculoesquelética. Rev. CEFAC. 2004 [acesso em 08 nov 2015]. [p. 24] Disponível em: http://www.cefac.br/library/artig os/532b6d8decce12f268ef6d79e7117f2a.pdf

18. Hilgenberg PB, Porto VC. Avaliação fonética em pacientes portadores de próteses dentárias. RGO - Rev Gaúcha Odontol. 2011;59(0):75-9.
19. Grupo de Trabalho instituído pela comissão de saúde do CFFa, Academia Brasileira de Audiologia e Sociedade Brasileira de Fonoaudiologia. BTTF: Balizador de Tempo de Tratamento em Fonoaudiologia. [acesso em 06 Mai 2015]. Disponível em: http://www.fonoaudiologia.org.br/ publicacoes/BALIZADOR\%20DE\%20TEMPO.pdf

20. Ayres A, Baltezan RL, Presotto M, Santos RB dos, Só MVR, Levy DS et al. Alterações Miofuncionais em Adultos e Idosos Usuários de Prótese Dentária. Rev. Fac. Odontol. Porto Alegre, 2012 [acesso em 08 nov 2015] 53(3):[p.6]. Disponível em:http://www.lume.ufrgs.br/bitstream/ handle/10183/115832/000954485. pdf?sequence $=1$ 


\section{Appendix 1}

(1) OROFACIAL MIOFUNCTIONAL EVALUATION PROTOCOL FOR DENTAL PROSTHESIS USERS

I - Interview

1 - Identification:

Name:

Age:

Birthdate:

Date of Examination:

Gender:

Profession:

Responsible dentist surgeon:

2 - For how long has the patient lost teeth and for which reasons:

3 -Time without dental prosthesis:

4 - Time with dental prosthesis:

5 -Does the patient present difficulties in fitting the prosthesis? Which difficulties?

6 - Did the patient have speech problems before using the prosthesis? Which difficulties?

7 - Does the patient have speech problems today? Which difficulties?

8 - Does the patient have masticatory problems? Which difficulties?

9 - Does the patient have hearing problems? Which difficulties?

10 - Does the patient have habits like:

Onicofagy ( ) Putting objects in the mouth ( ) Biting lips ( ) Biting the tongue ( ) Biting the cheeks ( ) Gnashing of teeth ( )

Notes:

II - Examination:

1 - Observation Data:

Frontal and profile analysis of the face:

a-tensions: frontal ( ) mentual ( ) cheeks ( ) lips ( ) peribucal region ( ) Notes:

b - symmetry ( ) asymmetry ( )

Notes:

III - Craniofacial Characteristics (evident data):

1 - Face: short ( ) medium ( ) long ( )

Upper third portion medium third portion

2 - Profile: straight ( ) concave ( ) convex ( ) biprotruso ( ) lower third portion

Notes:

IV - Verification of structures and musculature:

1 - Lips

( ) closed, competent.

( ) semi-opened

( ) fully opened

( ) tightly closed

( ) upper lip protrusion

( ) lower lip protrusion

( ) contraction of the lower lip

( ) contraction of the upper lip

( ) symmetric

( ) assymmetric

( ) marks on the mucosa

Which? 
Tensioned upper lip frenulum ( ) long extension ( ) normal extension ( ) Tensioned lower lip frenulum ( ) long extension ( ) normal extension ( )

2 - Orbicular of the mouth:
( ) satisfactory
( ) functional hypotonia
( ) functional hypertonia
Notes:

3 - Cheeks:

( ) symmetric

( ) assymmetric

( ) internal marks or wounds

( ) more enlarged on the right side

( ) more enlarged on the left side

( ) both sides equally enlarged

( ) right side of the face drooping

( ) left side of the face drooping

( ) both sides drooping

( ) compressed

4 - Buccinator:

( ) Balanced contraction of both sides

( ) Functional hypotonia of the left side

( ) Functional hypotonia of the right side

( ) Functional hypotonia of both sides

( ) Functional hypertonia of the left side

( ) Functional hypertonia of the right side

Notes:

5 - Masseter:

( ) Balanced contraction of both sides

( ) Functional hypotonia of the left side

( ) Functional hypotonia of the right side

( ) Functional hypotonia of both sides

( ) Functional hypertonia of the left side

( ) Functional hypertonia of the right side

Notes:

6 - Jaw: in normal position ( ) retruded ( ) protruded ( )

7 - Jaw: normal ( ) narrow ( )

8 - Mentual: without contraction ( ) with contraction ( )

9 - Tongue:

( ) normal

( ) extended

( ) without tip

( ) presence of marks on the sides

( ) presence of marks on the palatal papilla

( ) presence of marks in the inferior alveolar region

( ) compressed

( ) between the teeth

( ) between gingival ridges

( ) normal frenulum

( ) short frenulum

( ) filling edentulous areas

10 - Hard palate: normal ( ) ogival ( ) low ( )

11 - Soft palate: good mobility ( ) anterior vomit reflex ( )

12 - Tonsils: present ( ) absent ( ) increased ( )

13 - Intraoral space: normal ( ) increased ( ) decreased ( ) 
V - Mobility:

1 - Lips:

Protrusion ( ) Retraction ( ) Lateralization: R( ) L ( ) Elevation ( )

Notes:

2 - Tongue:

Protrusion ( ) Retraction ( ) Lateralization: R ( ) L ( ) Snap ( )

Notes:

VI - Mandibular movements: (measures, deviations, limitations, noises, pain)

1 - Opening: deviation $\mathrm{R}(\mathrm{)})$ deviation $\mathrm{L}(\mathrm{l})$ limitations ( ) noises ( ) pain ( )

Notes:

2 - Closure: deviation R ( ) deviation L ( ) noises ( )

Notes:

3 - Maximum aperture: measure:

4 - Laterality L: measure:

increased ( ) decreased ( ) relative to the right;

with stability of the prosthesis ( ) without stability of the prosthesis ( )

Notes:

Laterality R: measure:

increased ( ) decreased ( ) relative to the right;

with stability of the prosthesis ( ) without stability of the prosthesis ( )

Notes:

5 - Protrusion: measure:

present ( ) absent ( ) with deviation ( )

Notes:

VII - Stomatognathic Functions:

1 - Breathing: nasal mode ( ) predominantly oral ( ) difficult nasal breathing ( )

Notes:

2 - Mastication: bilateral ( )

left unilateral predominance ( )

right unilateral predominance ( )

presence of previous cut: yes ( ) no ( )

presence of coalescing movement ( )

Notes:

3 - Swallowing:

with labial tightening ( ) with visible projection of the tongue ( )

with liquid leakage ( ) with head movement ( )

Notes:

Filmed ( ) Date: Photographed ( ) Date:

Diagnosis:

Conduct: 


\section{(2) LIST OF PHRASES: SPEECH ANALYSIS}

1. Karina has class in the morning

2. Rats hide from cats

3. Plínio crashed the car in a block

4. The wrapping paper is large

5. The clown was crying in the rain

6. A good smell was coming from the kitchen

7. I looked at the fat cat and laughed

8. James was dancing with Janice

9. Tomorrow we will leave without fail

10. I got the potato in the truck

11. The food never ends

Balanced phrases proposed by Felício (1996) and taken from Cunha (2004).

\section{(3) PRONUCIABILITY OF PHRASES}

Directions:

This experiment will take 30 minutes or less of your time and you will be collaborating with our research. The results will not reveal ethe name of any participant. The task you will perform will not be difficult to complete. But if at any point you wish to interrupt the experiment, let us know and it will be stopped and suspended.

We are interested in studying how people find it difficult to say a few sentences. You should give a maximum score (10) for the sentence that was the most difficult to pronounce. Then you must give a score for each sentence, according to the difficulty to pronounce them, compared to the previous most difficult sentence.

This score can range from 0 to 10 . For example, if you find that a sentence is the most difficult to pronounce, rate it 10 . If you find you have minimal difficulty, rate it 0 . You can use any of the scores $(1,2 \ldots)$ and fractions $(1.5 ; 2.25 \ldots)$

If you find that two sentences have the same difficulty to pronounce, you can repeat the scores.

Remember that score 10 indicates the most difficult pronounciation and 0 indicates least difficult pronounciation.

\section{WORD LIST:}

\begin{tabular}{|l|l|l|}
\hline \multicolumn{1}{|c|}{ PHRASES } & MOST DIFFICULT PHRASE TO PRONOUNCE & DIFFICULTY SCORE FOR EACH PHRASE \\
\hline 1. Dad asked for popcorn & & \\
\hline 2. The armadillo dwells in the lair & & \\
\hline 3. Cacá wants cokes & & \\
\hline 4. The nanny kisses the baby & & \\
\hline 5. Didi's finger hurt & & \\
\hline 6. Gugu likes the cat & & \\
\hline 7. Filó made a tape & & \\
\hline 8. The saci knows how to whistle & & \\
\hline 9. The kettle is full of tea & & \\
\hline 10. Grandma dressed the dress & & \\
\hline 11. Zizi landed at Zezé's house & & \\
\hline 12. The jeep belongs to Juca & & \\
\hline 13. Mom ate papaya & & \\
\hline 14. The baby swims in the pool & & \\
\hline 15. The little bird ate the worm & & \\
\hline 16. Roberto drives the car fast & & \\
\hline 17. Lili licked the lemon & & \\
\hline 18. The tree bears fruit and flowers & & \\
\hline 19. Dislon drives by day & & \\
\hline
\end{tabular}

Phrases proposed by Berretin (1999), taken from Cunha (2004). 


\section{Appendix 2}

\section{Characterization of oromiofunctional exercises used in the speech therapy}

\begin{tabular}{|c|c|c|c|c|}
\hline $\begin{array}{l}\text { TYPE OF } \\
\text { EXERCISE }\end{array}$ & $\begin{array}{l}\text { STRUCTURE } \\
\text { INVOLVED }\end{array}$ & OBJECTIVE & $\begin{array}{l}\text { FREQUENCY X } \\
\text { DURATION }\end{array}$ & STRATEGY \\
\hline \multirow[t]{2}{*}{ ISOMETRIC } & Tongue & $\begin{array}{l}\text { Strengthening lingual } \\
\text { musculature }\end{array}$ & $\begin{array}{c}5 \text { to } 10 \text { times from } 3 \text { to } 10 \\
\text { seconds. * }\end{array}$ & $\begin{array}{l}\text { Through the isometric exercise } \\
\text { of tongue sucked on the palate, } \\
\text { keep "x" sec and snap. - exercise } \\
\text { proposed by Rahal (2012). }\end{array}$ \\
\hline & Cheek & $\begin{array}{l}\text { Strengthening the buccinator } \\
\text { muscle }\end{array}$ & 5 series of 15 seconds & $\begin{array}{l}\text { Through the request to inflate } \\
\text { cheeks and sustain. }\end{array}$ \\
\hline \multirow[t]{2}{*}{ ISOTONIC } & Tongue & Adapt tongue mobility & $\begin{array}{c}3 \text { to } 7 \text { series of } 10 \\
\text { movements in the rhythm } \\
\text { of one second, with } \\
\text { interval of } 10 \text { seconds } \\
\text { between the series. }\end{array}$ & $\begin{array}{l}\text { Through the request of antero- } \\
\text { posterior exercises of tongue } \\
\text { sucked against the palate. - } \\
\text { Exercise proposed by Berrentin- } \\
\text { Felix, Silva \& Mituuti (2012) }\end{array}$ \\
\hline & Cheek & $\begin{array}{l}\text { Working the buccinator } \\
\text { muscle mobility }\end{array}$ & $\begin{array}{l}5 \text { to } 7 \text { series of } 3 \text { to } 7 \\
\text { sequential movements. }\end{array}$ & $\begin{array}{l}\text { Through the exercise of sucking } \\
\text { and inflating the cheeks } \\
\text { simultaneously and alternately. }\end{array}$ \\
\hline \multirow{4}{*}{ ISOKINETIC } & Lips & Strengthening lip muscles & $\begin{array}{c}5 \text { to } 10 \text { times from } 3 \text { to } 10 \\
\text { seconds. * }\end{array}$ & $\begin{array}{l}\text { Through counter-resistance } \\
\text { with the use of a spatula in lip } \\
\text { protrusion. }\end{array}$ \\
\hline & Tongue & $\begin{array}{l}\text { Strengthening lingual } \\
\text { musculature }\end{array}$ & $\begin{array}{c}5 \text { to } 10 \text { times from } 3 \text { to } 10 \\
\text { seconds. }\end{array}$ & $\begin{array}{c}\text { Through counter-resistance with } \\
\text { the use of a spatula in tongue } \\
\text { protrusion. ** }\end{array}$ \\
\hline & Cheek & $\begin{array}{l}\text { Strengthening the buccinator } \\
\text { muscle }\end{array}$ & $\begin{array}{c}8 \text { to } 10 \text { times from } 5 \text { to } 10 \\
\text { seconds. } \\
\text { (the hypotonic side will } \\
\text { have a duplicate number } \\
\text { of replicates relative to the } \\
\text { normal side). }\end{array}$ & $\begin{array}{l}\text { With closed teeth, the therapist } \\
\text { will place the index finger on the } \\
\text { inside of the cheek and force it } \\
\text { out. The patient should force the } \\
\text { closure of the cheek performing } \\
\text { similar movement to that of } \\
\text { suction. }\end{array}$ \\
\hline & Masseter & $\begin{array}{l}\text { Strengthening the masseter } \\
\text { muscle (side depending on } \\
\text { each patient) }\end{array}$ & $\begin{array}{c}5 \text { to } 10 \text { times from } 5 \text { to } 15 \\
\text { seconds. }\end{array}$ & $\begin{array}{l}\text { Through the tip of the tongue in } \\
\text { the region of the incisive papilla } \\
\text { maintaining the support of buccal } \\
\text { opening and hands supported in } \\
\text { the inferior region to the mandible } \\
\text { performing counter-resistance } \\
\text { (attempt of buccal closure). }\end{array}$ \\
\hline
\end{tabular}

* Muscle contraction time gradually increased throughout the sessions.

** This exercise was not performed in the case of patients who had previous lisp. 